\section{SEVERE HAEMOPTYSIS TREATED BY MEANS OF THE ICEBAG.}

By HAROLD DOWNE S, M.B EdIN, L.R.C.P., PHYSICIAN TO BELLEFIELD SANATORIUM, LANARK.

The following case seems to be of interest as an illustration of a method of treatment which has largely gone out of use :

The patient, W. B , labourer, age 28, was admitted to Bellefield Sanatorium on March 12 th, 1907. 'There was a history of a considerable haemorrhage eight years ago, but details were wanting. Since then he seems to havie enjoyed good health up to August, 1906, when he hud a fresh haemorrhage, which con tinued for some days; from that time to the present he has been in failing health, suffering from cough and weakness, has been unable to do any work, and bas been in poor circumstances in consequence. He has lost about a stone in weight.

On examination he was found, in spite of the old history, to bo suffering from phthisis in a comparatively early stage. The cough and expactoration were slight, tempersture normal, pulse 70. On the right side there was some flattening below the clavicle, with limitation of movement ; slight dullness 6xtended to the level of the third rib in front and correspondingly behind; vocal resonance was slightly increased over this area, the breath sounds were bronchial, and a fow deep-seated crepitations were heard about the level of the third rib in the mammary line. The base was clear. The left lung was practically normal with the exception of slight dullness at the base, with faint breathing, probably indicative of former pleurisy. The heart sounds were norcal, except for accentuation of the second sound in the pulmonary area ; the arterial walls were slightly thickened, and. the pulse tension was somewhat incressed. The urine was normal.

He was kept in bed, and given a fall diet, including a liberal allowance of meat and four pints of milk a day. On March 16th (four days after admission) the sputum was increased in quantity and tinged with blood, and the same was observable on the fcllowing day. On March 19th definite haemorrhage set in. This continued at fairly regular intervals of $\mathrm{few}$ hours for a period of nine dars. the quantity of blood lost at a single haemorrbage varying from $1 \frac{1}{2}$ to $15 \mathrm{oz}$, the total ismoun being.almost 8 pints. The daily quantities were as follows :

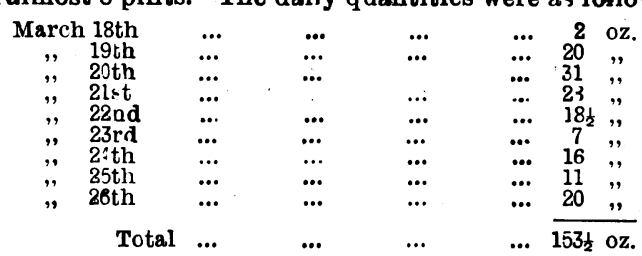

The temperature fluctuated from $99^{\circ}$ to $101^{\circ} \mathrm{F}$ The patient throughout was remarkably philos opbic. The only alteration in the physical signs was an increase in the number of crepitathons over the area already noted, end the development of a ceepstant area at a corresponding polnt behind. No evidence ceppitant area at a corresponding point behind.

The treatment included sbsolute rest with the shoulders The thy raised, a diet of milk and eggs, ind rendild saline pprients. Hypodermic injections of morphine ( $\$$ gralo) were irwen first, but were discontinued as incireetas. Ampl Ittrito was administered in 3-minim capsales st frecuent intervals, bat appeared to have no effect. On the evering of March 26th an icebag was applied over the frontrof the ritht mper lobe, and kept continuously in position nitghenid day, the ice being frequently changed. Not a stagle drepof blood was expectorated from the time it was first applied. All drugs were stopped and the bag kept in place for six days. At the whof that period the chest was examined, and no crepltations corld be discovered. The patient is now (twelve weeks ister the cessation of the attack) rapidly improving in health, has gained $15 \mathrm{lb}$. in weight, and has no cough or expectoration.

The treatment of haemoptysis by means of the icebag is of course far from being a novelty, but of recent years it has largely been discontinued. I have frequently made are of the outward application of ice in euch cases, but without very convincing results. It is seldom that the bleeding point can be localized with sufficient sccumesy for the ice to be applied directly over the seat of the hacemorthage, and thus to : pooduee reflex oontanction of the pulmonary vessels in the affected lobule. If applied in the wrong place, it prebalily does harm by raising the blood. pressure in the region : of the haemorrhage. In the case under consideration, there is little doubt that the blood was coming from a minute cavity situated deeply in the lower portion of the right upper lobe, since there was no sign of breaking down of lung tissue in any other situation. In such cases the local application of the icebag would seem to be a metbod of treatment worthy of more general adoption.

\section{GOÎTRE OPERATIONS UNDER LOCAL ANAESTHESIA.}

By A. J. FAIRLIE CLARKE, M.A., M.B., 'M.C., F.R.C S.,

LATE RESIDENT SURGICAL OFFICER, THE GENERAL HOSPITAT,

I do not advocate local anaesthesia as a routine practice in gcitre operations. Most patients who undergo operations for enlarged thy roid glands take general anafsthetice satisfactorily (though it is not always possible to say beforehand which patients will not do so), so there is no need to submit the majority of these patients to the discomfort and anxiety of an operation under local anaesthesia. But for those patients whose condition makes general anaesthesia risky, or for those surgeons who shrink from giving general anaesthetics to patients of this class, I am sure that much good can be done with local anaesthesia.

During the last two years I have had opportunities of using a local anaesthetic for a number of severe goitre operations, and the results have been satisfactory. I do not claim any originality in this method. I have merely tried to follow the advice given by Professor Barker in the British Medical Journal of December 24th, 1904. The needles I have used have been his and the solution that which he recommendssodium chloride 12 $3 \frac{1}{2} \mathrm{oz}$; this is boiled, and then 10 minims of commercial adrenalin solution are added. The solution is ready for injection as soon as cool enough. The injection is made in two parts, superficial and deep. The superficial injection is made about the middle of the line of the proposed operation wound with a long, sharp needle; by passing the needle through the subcutaneous tissue and injecting at different points, the whole site of the incision can be dealt with through a single puncture. It is well to inject high up and to the outer side of the incision line, so that the nerves may be dulled on the proximal side of the wound. Half of the $3 \frac{1}{2} \mathrm{oz}$. of fluid are injected superficially. For the success of the deep injection I think it important to introduce the fluid behiad (the transverse layer of the cervical fascia, so that it may reach the nerves which compose the cervical plexus. To this end I have been accustomed to make a deep stab puncture with a sharp tenotomy knife-if possible, through akin already anaesthetized, behind the posterior border of the sternomastoid muscle at the junction of its upper with the second fourth. The puncture is made here to be above the point at which the spinal accessory nerve emerges from the muscle. One of Professor Barker's flexible blunt-pointed steel needles is then passed along the track of the tenotome de eply into the neck, and the remaining half of the fluid injected here. This is done with the special syringe made to fit these thin flexible needles. If need be, the process may be carried out on both sides of the neck at once, $3 \frac{1}{2}$ oz. of the fluid being injected on each side.

The injection, apart from the punctures, does not seem painful, though some patients complain of fallness in the prost during the deep injections. All this injecting can be done with the patient in bed, and after a brief delay she may be moved to the operating room, where the operation should begin not sooner than half an hour from the commencement of the injection. The anaesthesia will last for at least an hour after the commencement of the operation.

The oedema produced in the tissues is often considerable, but is seldom troublesome to the surgeon, for the bloodlessness of the tissues due to the adrenalin compensates for the inconvenience so caused. The operations done have been excisions of half the thyroid gland or ligature of both superior thyroid arteries. The arteries were found without difficulty.

During the operation the patient's face, unless she prefer not, should be covered with a piece of lint,'so as to hide the operator from view. She may drink tea, brandy and water, or other fluid during the operation, and this may divert her mind from what is going on. The moral control of these patients has been remarkable ; in no instance of a goitre operation have I seen trouble given by the patient.

The results of the anaesthesia have been surpristngly good. The patients experience little inconvenience; except 
when the trachea is dragged; then they complain of choking. One b>y of 16, who otherwise showed no sign of discomfort, att-mpted to vomit when the gland was dragged away from the trachea. One woman whose superior thyroid arteries were tied for exophthalmic goitre, and whose condition with small, frequent pulse put general anaesthesia out of the question for her, bore the operation well, and said afterwards that the only painful steps in the procedure were the punctures for the deep injections. With all operations under local anaes thesia the patient's condition on her return to bed is much better than after general anaesthesia; all the post-anaesthetic distress is avoided. I have seen one goi tre patient vomit during the day of operation, but no other has shown ill effects which could be attributed to the drugs injected. Another had a high temperature with frequent pulse-rate for a day, but I do not put this down to the eucaine or adrenalin. Healing is not hindered by the injection.

I thank the surgeons to whose patients I have referred, both for their permission to publish these few notes and for their help in carrying out the process of anaesthesia at the times of their operations.

\section{THE ECLECTIC TREATMENT OF LUPUS VULGARIS:*}

Br J. GOODWIN TOMKINSON, M.D., ASSISTANT MRDICAL RLECTRICIAN, GLASGOW WESTERN INFIRMARY.

Dr. Mackintosh has very kindly asked me to show some of the patients suffering from cutaneous diseases who have been treated in the electrical department of the Western Infirmary.

With your permission, I would like to make a few remarks bearing upon the treatment of lupus valgaris, and, for purposes of illustration, I would draw attention particularly to three of the patients who have been under treatment for that clinical form of cutaneous tuberculosis.

CAQE I.

R. C., a farm servant, aged 23, entered the electrical department on March 29th, 1906, suffering from lupas valgaris exedens of the nose. His family history was good. He bimself had enjoyed good health until about four years ago, when he began to suffer from a sensation of obstructed respiration in the right nostril. Eramination on admission revealed a lesion occupying in the main the right ala nasi, the tip, and the lower half of the middle third of right half of the nose. There was more or less redness and swelling of the greater part of the organ, with a few vesico-pustular points here and there and considerable desquamation. The sebaceous glands, where visible, were widely dilated and plugged with comedones There was slight loss of tissue at the middle of the margin of the right als nasi with some ulcerstion. The mucous membrane of the right nostril was involved. There was right epiphora. Pressure with a microscope slide revesled "apple jelty" or "sucre d'orge" areas. Prior to admission he had been under treatment for lupus vulgaris. With 2 lesion in such a situation the treatment obviously indicated was-first, that which would most likely ensure the best cosmetic results namely, the least possible loss of tissue and the development of smooth and. flexible cicstrices; secondly, rapidity of cure or of Improvement.

There is no doubt as to the excellent quality of the cicatrix resulting from the Finsen treatment, but the length of time involved in its app' iostion is cslculated to exhaust the patience of. an individual immediately dependent upon his daily exertions for his living.

For three weeks, however, the patient was submitted to that treatment (Lortet and Genoud lamp) in so far $\mathrm{ss}$ the nonulcerated parts were concerned. In three weeks' time the $x$ rays were called into use with resulting rapid record of improvement. The light treatmont, however, was not entirely abandoned, and until July 28th, when the patient was dismissed (with instructions to return in three months' time or earlier, if necessary) he was under both forms of treatment. In addition, the nasal mucous membrane was painted daily, or less frequently, according to tolerance, with pure lactic aid, and a weak salloylic acid ointment was continuously applied to the whole lesion. The general health was assisted applied to the whole lesion. The general health was assisted
by the internal administration of syrup of the iodide of iron and an oocasional sal ine cathartic. In the middle of July he spent a whole week at sea. In all he was under active treatment for about four months. Three months af ter dis. missal he returned for inspection. All swelling and virtuslly all redness had disappesred "the epiphora had greatly diminished, and the ulcersted area was replaced by 8 :smooth and

* Read before the Western Division of the Glasgow and West of very regular cicatrix. Some further treatment is still neces sary, but the result at present is very satisfactory.

Case II.

I. M. a married woman, aged 23, was admitted to the electrical department on March 5th 1906. One of her brother had suffered from hip-joint disease. The disesse-lupus valgaris of vegetating alcerstive type-for which she sought relief commenced about eleven years ago as a circumscribed swelling in the left malar region. In spite of treatment, $i$ had been steadily progressive. On admission, the affected ares was found to occupy the greater part of both cheeks, virtually the whole of the nose- of which there was considerable loss of tissue-and the upper lip. The centre of the right cheek exhibited an area of about the of the right cheek exhibited an area of about the size of a florin covered with vegetations, purulent
discharge, and some crusting. The surrounding parts were markedly injected and somewhat swollen. A the junction of the nose and lip the tissues were broken down, while the lip itself was much swollen, more or lores with consequent ectropion of slight degree. There was some crusting at the lower limit of this area. The same eclectio crusting at the lower limit of this area. The same eclectic methods were adopted in this as in the other two cases. The non-ulcerated areas were exposed to the Finsen light, while
the vegetating and ulcerated parts were treated by the $x$ rays. The vegetating area at the onset of treatment gave consider able trouble, the associated inflammatory action, due doubtless to secondary infection, sometimes being very intense. Wet boracic dressings frequently applied were found to be of considerable allevistive value, and in a relatively short time the vegetations flattened down, and by the end of Jane the patient had so much improved that she went home for five weeks. On her return the area which at the onset of trestment was covered with vegetations showed a smooth cicatrix of very flexible quality, and the ulceration in the naso-labial region recommenced, but since October 2nd the Finsen light hss boen discontinued.

With a view to the reducing of the widespread hyperaemia, which was a marked feature at the onset of treatment. a lotion containing zinc oxide and calsmine with a little ichthyol was used; also, it should be added, salicylic acid in the form of plaster, rarely, and as a weak ointment more frequently, have been employed. The local treatment has been supplemented from time to time by the internal administration of haematinics and cod-liver oll, and saline aperients when indicated. Since March 5th, 1906, the patient has bad about seven and a half months of active treatment. Although some further treatment is necessary, the result so far is eminently satisfactory, especially when considering the revolting aspect presented by the patient at the time she arrived for treatment.

Obviously the $x$ rays have been in the main responsible for the relative rapidity of improvement in both of these cases-a rapidity which was strikingly apparent in the first case described.

\section{CASE III.}

J. D., a domestic servant, aged 27, who has suffared from lupus vulgaris of the right maxillary and submaxillary region for many years, and who bas a distinctly tuberculous family history, commenced trestment in the electricsl department on J anuary 3rd, 1902. She has had virtually all forms of light treatment-the Finsen, the iron electrode lamp, and the $x$ rays. The upper limit of the sffected srea hss c intinued, however, more or less rebellious to treatment. Latterly this has been largely overcome by the alternation of $x$-ray treatment with a largely overcome by the alternation of $x$-ray treatment with a removing as much of the disessed tissue as possible by the use of a strong salicylic acid plaster, the subeequent application of ichthy ol in ointment and lotion, till the irritation more or less subsid $\mathrm{s}$, and thereafter repeated cauterlzation by 80 per cent. pbenol in sbsclute slcobol, the strength advocated by $\mathrm{Dr}$. Billet of the good results of whose treatment for lupus vulgaris I had visible evidence some time after hearing his puper at the Paris Congress on Tuberculosis, held las $;$ year.

In conclusion, judging from patients who have been under my own personal treatment and from the experience of others, the $x$ rays are a very valuable addition to the dermatologist's armamentarium for the treatment of lupus vulgaris. Unfortunately, some cases appear to be at present altogether irresponsive to their curative action, but, on the other hand, there are cases which respond with relative rapidity and with the production of a cicatrix of high aesthetic value, as the first two cases demonstrate. Almost all are agreed as to the benefits resulting from the Fingen treatment in cases of limited extent, but the length of time demanded in the treatment of extensive areas considerably restricts its practical value in such cases. The older methods undoubtedly still play an important rôle in the therapentics of cutaneous taberculosis, and, along with the newer ones, should be recognized and employed as mutual adjuvants. 